\title{
Procesos de aprendizaje y modernización productiva en el agro del noroeste de México: Los casos de la agricultura comercial de la Costa de Hermosillo, Sonora y la agricultura orgánica de la zona sur de Baja California Sur ${ }^{1}$ Abel O. Villa Rodríguez* y Álvaro Bracamonte Sierra**
}

\section{Resumen}

El proceso de apertura comercial ha propiciado importantes cambios en el agro mexicano; muy notorios en el patrón de cultivos y en el marco institucional que ordena las relaciones de producción y comercialización del campo. La agricultura del noroeste de México, en particular la ubicada en la Costa de Hermosillo en el estado de Sonora y la del sur de Baja California Sur, exhibe evidentes transformaciones. Éstas se enmarcan dentro de la operación de las llamadas "redes globales de producción" (RGP) y en el contexto de un proceso de integración vertical que deriva en intensas interacciones extraterritoriales que propician el escalamiento competitivo. En ese sentido, el aprendizaje y la creación de nuevas habilidades productivas son indispensables para cumplir con los estándares de calidad exigidos en los mercados globa-
Abstract

The process of open markets has created import changes in the Mexican agriculture sector, very much noted in the so called crop pattern, the institutional frame that guides the agro-productive commercial relationships and trade organization. The agriculture in the Northwest region, particularly La Costa de Hermosillo in the State of Sonora and southern Baja in Baja Peninsula, shows a big transformation. This corresponds to Global Production Networks (GPN), a vertical integration with intensive extraterritorial interaction resulting in a process of productive escalation that favors; learning and the creation of new competitive capabilities indispensable to comply with high standards in international markets. These capabilities are reflected in improvements in product quality, productive efficiency and the development of new functions for

1 Ponencia preparada para el III Congreso Nacional de Ciencias Sociales, organizado por el Consejo Mexicano de Ciencias Sociales (Comecso) del 26 de febrero al 1 de marzo de 2012 en la ciudad de México.

* Maestro en Ciencias Sociales por El Colegio de Sonora. Correo electrónico: abel_ villa@mail.com.

** Doctor en Ciencias Económicas y profesor-investigador del Centro de Estudios de América del Norte de El Colegio de Sonora. Correo electrónico: abraca@colson. edu.mx 
lizados. Se compite en el mercado mundial sólo si existen innovaciones en el producto, en las funciones de los actores involucrados en la producción y comercialización agropecuaria y también se compite si se generan innovaciones a nivel del proceso. En las regiones agrícolas referidas es visible el paso hacia unidades de producción más sofisticadas, donde intervienen actores cuya actividad central se localiza en otros territorios. Este estudio analiza el papel de las RGP en la transformación del campo del noroeste de México. En particular, el objetivo es analizar justamente el proceso mediante el cual se modernizó la agricultura de ambas subregiones.

Palabras clave: redes globales de producción, escalamiento competitivo, agricultura orgánica, agricultura convencional, tecnología. the players involved in the production and trade of produce. It also reflects the transition to more sophisticated productive units where players are located in other territories. This study focuses on analyzing the roll of GPN in the transformation of the agricultural sector in the northwest region of Mexico, particularly the process that took place in modernizing both places.

Keywords: global production networks, competitive escalation, organic agriculture, conventional agriculture, technology.

\section{Introducción}

El proceso de apertura comercial ha propiciado en los últimos 25 años importantes cambios en el agro mexicano. Es notoria la modificación en el patrón de cultivos y en el marco institucional que ordena las relaciones de producción agropecuaria; pero sobre todo ese proceso se observa en el ámbito de la organización de la comercialización agrícola. Éstos se enmarcan en lo que Gereffi llama "redes globales de producción" (RGP) que supone una integración al comercio mundial (articulación vertical) liderada por los "brokers internacionales". De las intensas interacciones extraterritoriales que se derivan de la operación de las RGP, surgen procesos de escalamiento productivo que favorecen, de acuerdo con Kaplinsky y Readman (2001), el aprendizaje y la creación de nuevas habilidades competitivas indispensables para el cumplimiento de los estándares exigidos en los estrictos mercados globalizados: estos requerimientos se expresan 
en mejoras en la calidad del producto, en la eficientización de los procesos productivos y en el desarrollo de nuevas funciones para los actores involucrados en la producción y comercialización agropecuaria. La agricultura del noroeste de México, en particular la ubicada en la Costa de Hermosillo en el estado de Sonora y la localizada al sur de Baja California Sur, exhibe una transformación notable. En estas regiones es visible el paso hacia unidades de producción más sofisticadas, donde intervienen actores cuya actividad central se localiza en otros territorios. Dichos actores actúan en redes globales y sirven de puente para adaptar los procesos productivos localizados en remotas zonas agrícolas a las necesidades del mercado internacional. Este estudio trata de analizar el papel de las RGP en la transformación del campo del noroeste de México. En particular, el objetivo es analizar justamente el proceso mediante el cual se modernizó la agricultura de ambas subregiones. Para el cumplimiento de ese propósito se revisó la literatura especializada, se sistematizó la información estadística relevante, se realizaron entrevistas y se aplicó un cuestionario a informantes clave.

El documento se organiza en tres apartados. En el primero se aborda el marco conceptual de las redes globales de producción y su relación con el proceso de aprendizaje que presupone el escalamiento competitivo; estos conceptos serán referentes esenciales para el abordaje del objeto de estudio. En el segundo apartado se describen las zonas de estudio enfatizando la trayectoria seguida en la reestructuración y modernización orientada por el mercado externo; en el tercer apartado se analizan los elementos propios del aprendizaje que llevaron al escalamiento competitivo de ambas zonas agrícolas. Finalmente se exponen las conclusiones.

\section{Redes globales, aprendizaje, innovación y escalamiento competitivo}

La actividad agrícola es fundamental para el desarrollo sostenible de las regiones y al mismo tiempo es un vehículo que permite incursionar en los mercados globales gracias fundamentalmente al flujo de exportaciones que el sector genera. En este proceso tiene un papel central la operación 
de las llamadas "redes globales de producción" (RGP), definidas como "una combinación de redes interorganizacionales cuyos eslabones se entrelazan alrededor de una mercancía o producto, incorporando empresas y Estados en la economía mundial. Estas redes son socialmente construidas y localmente integradas" (Gereffi et al., 1994); para ello, es necesario observar estrictos estándares de calidad, especialmente los relacionados con la seguridad alimentaria. El cumplimiento de dichos requerimientos exige mejoras competitivas permanentes mismas que a su vez implican innovaciones en el producto, en los procesos productivos y en materia organizacional. Se trata en resumen de un escalamiento competitivo que implica aprendizaje tecnológico ${ }^{2}$ y capacidades innovativas de los agentes e instituciones que participan en ese circuito productivo. Para avanzar en esa discusión a continuación se analiza la distinción entre procesos de aprendizaje e innovación.

De acuerdo con Gereffi (1999) y Gibbon (2001), el escalamiento competitivo de los productores agrícolas globalizados comienza con la interacción entre el productor y los mayoristas internacionales; éstos proveen los apoyos necesarios (tecnología y conocimiento) para acceder a los mercados foráneos, cuestión que de otra manera sería complicado participar. Gereffi propone dos tipos de relación: 1) la impulsada por productores, y 2) la impulsada por compradores ${ }^{3}$ advierte que de dicha interacción dependerá la estructura de gobernanza, que dicta el cuánto, el qué y el cómo producir (Gereffi, 1999; Gibbon, 2001).

En la agricultura las RGP desarrollan un tipo de interacción comandada por los compradores. Como era de esperarse, todos los eslabones considerados en la red se rigen bajo una fuerte coordinación por parte del comprador, convirtiéndose éste en el responsable del escalamiento de cada uno de los agentes pertenecientes a la cadena. Humphrey (2005) sostiene que el liderazgo impulsado por los mayoristas o brókers internacionales se debe a su interacción con los supermercados. Son ellos precisamente los

2 "El aprendizaje es un proceso que envuelve repetición y experimentación, lo cual hace posible realizar las tareas mejor y más rápido, e identificar nuevas oportunidades de producción. Es el proceso a partir del cual las empresas crean conocimiento y adquieren capacidades tecnológicas" (Vera-Cruz y Dutrénit, 2009:176).

${ }^{3}$ Para abordar las RGP del sector agrícola utilizaremos la segunda relación, que se caracteriza por una producción intensiva en mano de obra, donde el diseño y la mercadotecnia tienen un gran potencial. 
que tienen conocimiento del cambio en la estructura del mercado meta, como son los patrones de consumo, las necesidades y las preferencias. Igualmente son ellos quienes exigen a los productores el complimiento de estándares de calidad, debido a preocupaciones no solamente referidas a la sanidad, sino también a la calidad, el cuidado del medio ambiente y las condiciones laborales (Humphrey et al., 2006; Humphrey, 2005).

Considerando que la gobernanza en el agro generalmente está determinada por los compradores, el escalamiento competitivo surge cuando los productores operando en segmentos de bajo valor agregado transitan hacia unidades productivas más sofisticadas (López y Gomis, 2004), proceso que está acotado por la acción de las RGP.

En este marco los esfuerzos realizados por los productores locales se concentran en ampliar su base de conocimientos y en la aplicación de nuevas tecnologías a fin de elevar la productividad y cumplir con los estándares sugeridos por los brókers. Es en esta etapa donde los agentes comienzan el proceso de aprendizaje (Kaplinsky y Morris, 2001) que implica conocer nuevas tecnologías a fin de diversificar el patrón de cultivos, mejorar los procesos productivos y desarrollar habilidades de su fuerza laboral (Dodgson, 1991).

A continuación se describen brevemente los tres ámbitos en los que el escalamiento competitivo, derivado del aprendizaje y la apropiación tecnológica, se expresa: productos, procesos y organizacional.

1. Productos: En lo que respecta al sector agrícola, este nivel de escalamiento deriva en cambios en la variedad del producto. Esto es, hacer cambios en el patrón de cultivos, los cuales deben tener un impacto significativo en su desempeño reflejándose en un incremento en los ingresos. Se trata del aumento en la eficiencia de los procesos internos con diferencias significativas respecto de los desarrollados por sus rivales.

2. Procesos: Ésta es la dimensión que recibe mayor atención. Su orientación se concentra en los cambios relacionados con las prácticas de campo y manejo poscosecha. También está relacionada con el manejo de la calidad a través de los estándares. Asimismo, se involucran actividades que resulten en la introducción de nuevos productos o en el mejoramiento de los ya existentes de forma versátil, o en la relación entre los diferentes eslabones de la cadena. 
3. Organizacional: Es la realización de nuevas actividades dentro de la empresa, por ejemplo, asumir la responsabilidad de logística, mercadotecnia, calidad y diseño. Se trata de delegar un conjunto de actividades a diferentes eslabones de la cadena de valor.

De esta manera, en la medida en que los productores innoven en esas modalidades de escalamiento competitivo cumplirán con los estándares implantados por las RGP, lo que se reflejará en el tránsito de formas de producción básicas a esquemas de mayor valor agregado. Sin embargo, Humphrey Memedovic (2006) advierten que esta trayectoria implica cuantiosas inversiones que a su vez deben complementarse con apoyos institucionales. Pero éste es otro tema que va más allá de los propósitos establecidos en esta investigación.

\section{La agricultura del noroeste de México: escalamiento competitivo y mercados globales}

La agricultura del noroeste de México es reconocida a escala nacional por su alta productividad, misma que ha sido el resultado, por una parte, de las duras restricciones climáticas que ha implicado a los productores ser más eficientes y, por otra, de una derivación del escalamiento competitivo exigido por los mercados globales que posibilita participar activamente en las RGP. El propósito de este apartado es caracterizar la evolución del agro en la región referida con el objetivo de establecer las transformaciones observadas en el último cuarto de siglo.

Para efectos de este estudio, la agricultura del noroeste de México se conforma del agro de la península de Baja California ${ }^{4}$ y de los estados de Sonora y Sinaloa. ${ }^{5}$ Esta región se caracteriza por reunir las más severas condiciones ambientales, mismas que a lo largo del tiempo han dificultado el aprovechamiento del recurso tierra. ${ }^{6}$ En algunas zonas es notable la pre-

${ }^{4}$ La península de Baja California incluye a las entidades federativas de Baja California y Baja California Sur.

${ }^{5}$ La delimitación geográfica del estudio corresponde al municipio de Los Cabos en Baja California Sur y la Costa de Hermosillo en Sonora.

${ }^{6}$ Dentro de estas condiciones se engloban características climáticas propias de la zona, 
caria calidad de los suelos y los típicos relieves abruptos, y son visibles las restricciones climáticas, mismas que en conjunto limitan de manera considerable el desarrollo agropecuario (Mora, 1981). A pesar de este hecho, se advierte una sustantiva expansión del sector. En sus inicios, en los campos del noroeste del país se aplicaron métodos de producción intensivos en mano de obra, se observó un patrón de cultivos reducido a uno o dos productos y el uso masivo de fertilizantes químicos, pesticidas y herbicidas. En ese tiempo la lógica de la acumulación giraba en torno a satisfacer las necesidades alimentarias derivadas de la creciente población mexicana.

Con el tiempo fue notoria la transformación de esa forma de producir. Esto fue fruto de las interacciones con los mercados globales, especialmente el norteamericano. Poco a poco esta región se consolidó a tal grado que se convirtió en la fuente principal de productos hortofrutícolas de la Unión Americana, principalmente en el invierno boreal. Este resultado naturalmente tiene que ver con las operaciones de las llamadas "redes globales de producción" en el sector primario. El involucramiento de los productores agrícolas locales a la dinámica marcada por las RGP, aunado a la elasticidad de la demanda para esos cultivos, permite comprender la metamorfosis experimentada por los productores y en general por la agricultura de la zona bajo estudio (Marsh y Runsten, 2000).

La producción de hortalizas y frutales, tanto convencionales como orgánicos, se ha afianzado en la región; ${ }^{7}$ la cosecha, casi en su totalidad, se comercializa en Estados Unidos, la Unión Europea, Canadá y Japón. El paso de un patrón de cultivos conformado exclusivamente por básicos a productos con mayor densidad en valor agregado supuso un considerable incremento en la productividad en los distritos de riego de la zona. ${ }^{8}$

En ese sentido, se abordarán dos regiones agrícolas que se destacan por su capacidad de adaptación a los imperativos de la integración económica y a la operación de las RGP. Para responder a la dinámica impues-

donde predominan los climas áridos y semiáridos, de acuerdo con la clasificación climática de W. Köppen (Mora, 1981).

${ }^{7}$ Principalmente en los municipios de Los Cabos, Baja California Sur; así como en Hermosillo y Obregón, Sonora.

${ }^{8}$ Comparando los valores de las tierras de temporal, se obtiene que su rendimiento está por arriba de la media nacional. En relación con el ingreso, muestran valores mayores de la media nacional, comparados con las zonas del sur del país. 
ta por los mercados internacionales es indispensable producir lo que los mercados demandan; para ello es necesario que los agricultores ajusten sus paquetes tecnológicos, introduzcan innovaciones y en general eleven la competitividad pues de otra manera serán desplazados de la lógica de acumulación anclada en los mercados globales. Las regiones seleccionadas se han destacado por su orientación al mercado externo y por la introducción de mejoras en los métodos de producción. Se trata, por un lado, de la agricultura desarrollada en la Costa de Hermosillo, Sonora, que se distingue por la aplicación de nuevas tecnologías y la diversificación productiva; y por otro, de la agricultura orgánica en la zona sur de Baja California Sur, presentada como una alternativa para la producción de una diversidad de productos demandados por los mercados internacionales que dan importancia al cuidado del medio ambiente en que se producen los cultivos (figura 1).

\section{Figura 1. Ubicación de las zonas de estudio. Los Cabos B.C.S. y la Costa de Hermosillo, Sonora}

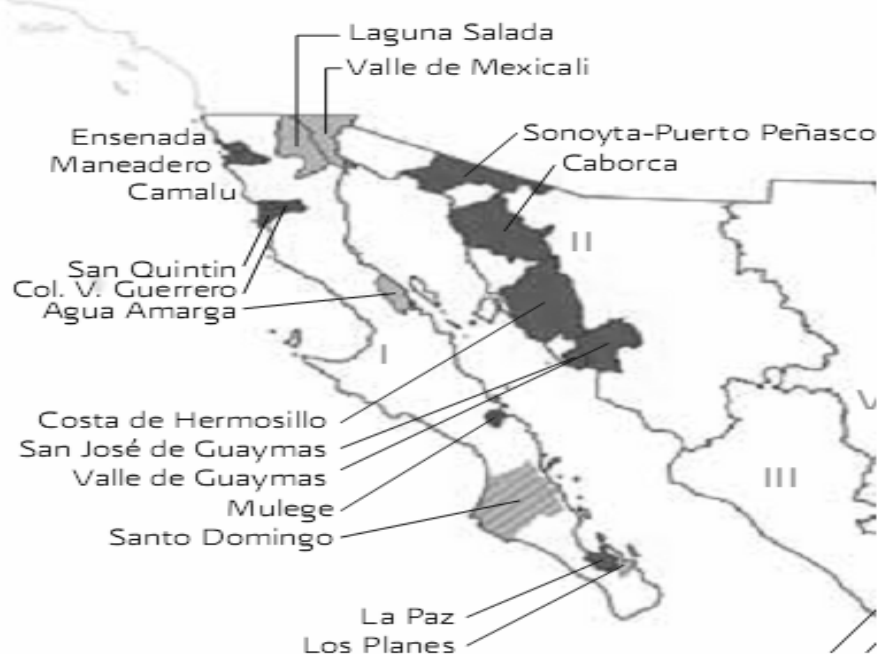

Fuente: Conagua, Subdirección General de Programación, 2010. 


\section{La agricultura en la Costa de Hermosillo}

El distrito de riego de la Costa de Hermosillo es una de las zonas agrícolas más importantes del noroeste de México, especialmente por su alta productividad. Se encuentra ubicado en el región centro-occidental del estado de Sonora, de clima semiárido que comprende 200000 hectáreas aproximadamente (Rodríguez, 2003). Actualmente es considerado un paradigma de modernización, dado su notable grado de tecnificación que ha elevado la producción expresada en el flujo de divisas y generación de empleos. La Costa de Hermosillo es un espacio privilegiado para observar la instrumentación de políticas de modernización orientadas a reactivar el agro mexicano (figura 2) (Martínez et al., 2002; Rodríguez, 2003).

Figura 2. Costa de Hermosillo: estructura

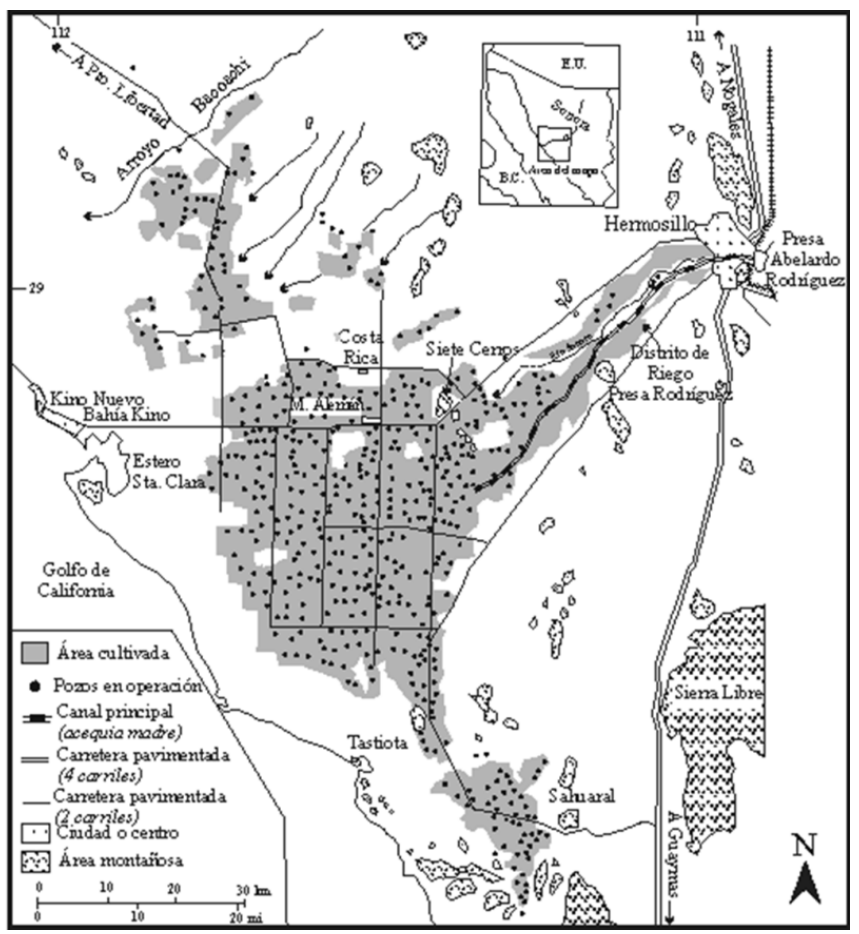

Fuente: Tomado de Moreno (2006). 
Pocas regiones agrícolas del país exhiben un desarrollo tecnológico tan robusto; su situación actual fue motivada y explicada por la aplicación de un esquema de acumulación capitalista rural y por la presencia de empresas transnacionales operando en la zona. De acuerdo con Mora (1981), Martínez (2002, 2003) y Estrada y Rodríguez (2007), la agricultura de esta región es la más mecanizada del país, pues $98 \%$ de la superficie cultivada cuenta con riego presurizado. En virtud de la sobreexplotación del recurso hídrico, ${ }^{9}$ la superficie sembrada ha decrecido desde la década de $1970 .{ }^{10}$ En este sentido, los esfuerzos se han concentrado en la búsqueda de un modelo de rentabilidad económica que generara ventajas comparativas con los socios comerciales. ${ }^{11}$

En esa exploración se conjugaron factores endógenos y exógenos que incidieron en el desarrollo de esta zona agrícola. Entre los primeros habría que anotar las duras condiciones climáticas y las políticas públicas sectoriales que favorecieron la transformación de la lógica productiva; en éstas sobresale la participación de los productores en las RGP, lo que originó la aplicación de un programa de reconversión que implicó el desplazamiento de granos y oleaginosas por productos hortofrutícolas. La ventaja que tienen estos productos es que generan mayor productividad por metro cúbico de agua. Actualmente la superficie de siembra es de sólo 40000 ha de las 120000 que había a mediados de los setenta del siglo pasado. La actividad hortofrutícola ocupa más de $90 \%$ de la producción y sólo $7.5 \%$ se destina a garbanzo de exportación y a trigo. Entre los cultivos que actualmente se siembran destacan la uva, el nogal, los cítricos y las hortalizas; ${ }^{12}$ la Costa de Hermosillo genera 30\% de los jornales de toda la agricultura sonorense; $30 \%$ de la producción agrícola de la entidad, $53.7 \%$ de las exportaciones agrícolas estatales y $31 \%$ del producto interno bruto (Рів) agrícola de Sonora. Estos datos revelan la naturaleza del campo en la Costa de

${ }^{9}$ El recurso hídrico que sustenta toda actividad agrícola en la zona procede del distrito de riego 051 (Estrada y Rodríguez, 2007).

${ }^{10}$ En la década de 1940 se promulgó el Decreto de colonización que comprendía el distrito de riego 051, con una extensión de 200000 hectáreas de superficie abierta (Asociación de Organismos Agrícolas del Norte de Sonora [AOANS]).

${ }^{11}$ Durante la década de 1970 y principios de la de 1990 se implementó un programa de reducción de extracciones (5\% anual). Para el ciclo agrícola 2009-2010 se contaba con 665 millares de metros cúbicos de los dos mil millares de metros cúbicos que se extraían (AOANS).

${ }^{12}$ Habría que señalar que $98 \%$ de la producción está en manos del sector privado. 
Hermosillo, misma que responde a la dinámica de mercado internacional y a las restricciones que el medio ambiente impuso.

En este contexto, desde mediados de las década de 1980, la presencia de empresas trasnacionales influyeron en la creación de nuevas formas de organización y relaciones entre productores y compradores, definiendo así las características del producto, con base en las necesidades de los mercados a los que van dirigidos y de los actores involucrados (Acosta y Avendaño, 2010).

\section{La agricultura de la zona sur de Baja California Sur}

En Baja California Sur el desarrollo agrícola depende exclusivamente del aprovechamiento de los recursos hídricos subterráneos. ${ }^{13}$ Esta condición la convierte en una de las más caras del país. Las limitaciones naturales han propiciado que los agricultores de la región sean más selectivos sembrando sólo cultivos altamente rentables, lo que exige maximizar la producción por unidad de superficie y orientar los planes de siembra en función de los precios establecidos por el mercado (Murillo-Amador et al., 2006). A partir de la década de 1980 se vieron los primeros signos de una transición progresiva con la entrada de empresas extranjeras, dando inicio a un cambio hacia formas de producción orientadas a las necesidades del mercado estadunidense.

Bajo este contexto, en 1986 surge el sistema de producción orgánica en el municipio de Los Cabos. Estaba orientado sobre todo a la hortofruticultura, ello debido a la creciente demanda del mercado norteamericano. La unión de esfuerzos entre actores locales y externos, mediante una sociedad inicialmente integrada por seis productores del ejido San José del Cabo y Jacob Bruce, ${ }^{14}$ constituyó un éxito, lo que animó a producir a otros ejidatarios de las cercanías (Murillo-Amador et al., 2006) (figura 3).

${ }^{13}$ Se constituyen por el almacenamiento de agua en la parte interna del subsuelo a diferentes profundidades. Ello demanda obras de infraestructura que permitan el bombeo de agua hacia la superficie. Sin embargo, por mucho tiempo predominaron los cultivos tradicionales como maíz y trigo, elementos distintivos de la agricultura del noroeste.

${ }^{14}$ Lorenzo Jacob Bruce, especialista en proyectos de desarrollo rural, y su esposa Sandra Belin son dueños y fundadores de la comercializadora Jacobs Farm localizada en San José California, en el área de la Bahía de San Francisco, Estados Unidos. 
Figura 3. Principales zonas de cultivos orgánicos en el municipio de Los Cabos

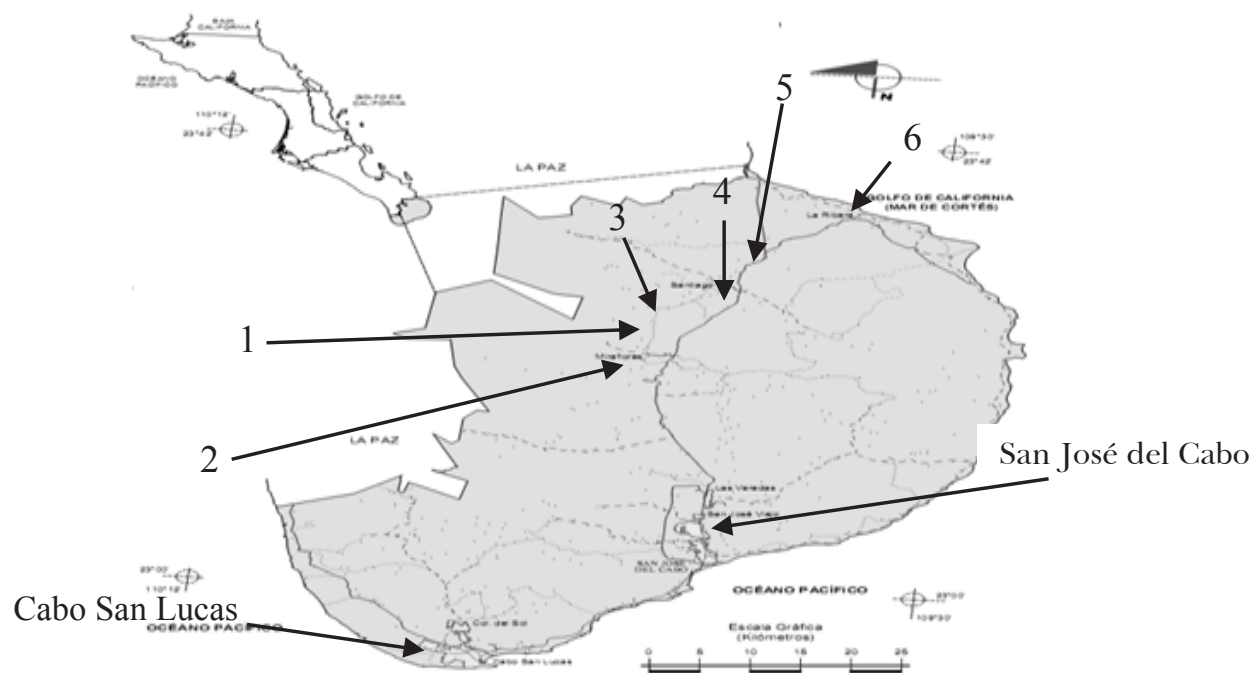

*Las Casitas (1), Miraflores (2), Santiago (3), Las Cuevas (4), Santa Cruz (5) y La Ribera (6).

Fuente: INegi, Prontuario de información geográfica municipal, Los Cabos, Baja California Sur.

El nuevo sistema de producción implicó la introducción de una nueva filosofía que privilegiaba el cuidado del medio ambiente; fue una salida interesante para el manejo del agua pues garantizaba la disponibilidad de ese recurso en el futuro. ${ }^{15}$ Este fenómeno llevó también a la asimilación de una cultura organizacional más eficiente, abierta a las exigencias de los consumidores y capaz de enfrentar la creciente competencia de los mercados globales.

Con la integración al mercado de Estados Unidos, la zona sur de la entidad, con características ambientales y geográficas propicias, atrae a más comercializadores e involucra a productores para abastecer el comercio minorista de hortalizas en el estado de California, Estados Unidos. Los productores de Baja California Sur consolidan así su participación en las

${ }^{15}$ La estructura debía dar respuesta a la problemática del abatimiento e intrusión salina ya presentes en los pozos de extracción, e incrementara la recarga de los acuíferos en las áreas agrícolas. 
RGP, donde hacen valer sus recursos para mejorar su posición a partir de la adquisición de nuevas funciones.

\section{Aprendizaje, innovación y escalamiento competitivo de la agricultura}

A continuación se discuten los procesos de innovación en las dos regiones agrícolas bajo estudio; igualmente, se analizan los mecanismos de aprendizaje tecnológico que hipotéticamente han facilitado el incremento de la competitividad en ambas zonas. Para ello se considerará la tipología analizada en la primera parte de este documento, esto es, el escalamiento o innovación en producto y procesos y en funciones organizacionales. Para la recopilación de información en ambas localidades se utilizaron dos instrumentos; su diseño busca reflejar las acciones implementadas por los productores encuestados en los tres niveles que engloban su operación. El primero fue un cuestionario ${ }^{16}$ que alude al escalamiento en procesos y funciones organizacionales, conceptos que articulan y guían esta investigación. El instrumento se compone por tres secciones. La primera, de datos generales, recaba información respecto del giro, la actividad así como el destino de la producción. La segunda, capacidad de absorción, busca detectar los mecanismos para generar y compartir el conocimiento, necesarios para dar lugar a la innovación. La tercera, aprendizaje e innovación tecnológica, recaba información acerca de la materialización del conocimiento en actividades innovadoras. ${ }^{17}$ Por su parte, el segundo ins-

${ }^{16}$ La formulación del cuestionario tomó como punto de partida el proyecto "Redes globales de producción y aprendizaje local. Derrama tecnológica de las transnacionales y capacidad de absorción en pymes de base tecnológica en el noroeste de México". El proyecto fue desarrollado en El Colegio de Sonora bajo la dirección del Dr. Óscar Contreras.

${ }^{17}$ Las actividades innovadoras son todas aquellas implementadas para la mejora en los tres niveles de escalamiento; éstas van desde investigación y desarrollo de nuevos procesos, diseño e ingeniería, adquisición de tecnologías incorporadas como maquinaria y equipo y no incorporada como patentes, licencias, know-how, servicios computacionales o científico-técnicos. Asimismo, aluden a la modernización organizacional orientada a mejorar la comercialización de los productos o servicios, introducción de nuevos diseños, análisis y búsqueda de nichos de mercado. 
trumento fue una entrevista semiestructurada con el objetivo de abordar los mecanismos de escalamiento competitivo a nivel producto. El número de productores encuestados se determinó con base en fuentes de información relacionadas con la producción, comercialización y certificación orgánica, a nivel regional o local.

La selección de la muestra para ambas localidades no obedeció a criterios estadísticos debido a la homogeneidad presentada por los grupos de productores. Para la Costa de Hermosillo, se encuestó y entrevistó a cinco de los 12 principales agricultores privados. En el caso de Baja California Sur, el número ascendió a 18 de un universo compuesto por 336 productores. ${ }^{18}$ La aplicación de los cuestionarios se desarrolló en julio de 2011 para la zona sur de Baja California Sur y en septiembre del mismo año para la Costa de Hermosillo.

\section{La agricultura moderna de la Costa de Hermosillo}

\section{Escalamiento competitivo a nivel producto}

Como se comentó antes, la agricultura de esta zona ha registrado un acelerado proceso de modernización expresado en el cambio de patrón de cultivos donde la hortofruticultura desplazó a los granos y las oleaginosas. Esta reconversión creó las condiciones para iniciar un cambio en la organización de la producción, incrementar rentabilidad, acceder a tecnología y actualizar la base de conocimientos y habilidades técnicas. Veamos en qué consistieron esos cambios.

\section{Mecanismos para la mejora del producto}

Tal como se mencionó en apartado previo, uno de los cultivos más sobresalientes es la vid de mesa. Esto se explica, en principio, porque es un cultivo altamente intensivo, con una producción estimada en 15 millones

18 La homogeneidad se basa en los criterios de las fuentes consultadas, tales como la Sociedad Mexicana de Producción Orgánica (Somexpro) y la Asociación de Organismos Agrícolas del Norte de Sonora (aOANS). Dentro de ellos destaca el tipo de certificación, tipo de cultivos y grupo comercializador al que pertenecen. 
de cajas por ciclo agrícola (AOANS). La ventana de comercialización es de sólo dos meses, correspondientes a mayo y junio; ${ }^{19}$ el número de países donde se coloca la producción asciende a 30, destacando algunas naciones de América del Sur, Asia, Unión Europea y Canadá, entre otras. Asimismo, la producción de cítricos ${ }^{20}$ como la naranja ha logrado una marcada diferenciación en su proceso de siembra ya que es el único cultivo de la zona que utiliza un sistema orgánico y convencional tanto para su producción como para su procesamiento.

Por su parte, el nogal o nuez pecanera ha mostrado un crecimiento importante en la zona; actualmente se encuentran cuatro mil hctáreas en producción y otras tantas en desarrollo. El mercado de destino es $70 \%$ nacional, principalmente en la ciudad de México; el resto se exporta —en los últimos tres años China se ha convertido en el segundo destino de exportación de la producción.

Las hortalizas se incorporaron recientemente al patrón de cultivos. Esto respondió a peticiones de parte de comercializadores internacionales que buscaban satisfacer la demanda de estos productos en nichos ya identificados. Por lo tanto, $100 \%$ de la producción es de exportación, además de ser un complemento para los productores; es decir, las hortalizas son una diversificación dentro de la cartera de productos de los agricultores de la zona.

\section{Escalamiento competitivo a nivel de proceso}

\section{Mecanismos para el desarrollo de habilidades}

de aprendizaje y mejora en los procesos

Dentro del escalamiento competitivo en procesos es posible clasificar tres tipos diferentes de mecanismos: 1) documentación de apoyo, 2) acciones

${ }^{19}$ Debido a que las condiciones de temperatura para su cosecha deben ser de 45 grados Celsius.

${ }^{20}$ Se advierte una marcada tendencia a incrementar la superficie bajo este sistema de producción debido a la creciente demanda por productos sanos, libres de residuos químicos en mercados como la Unión Europea, Japón, Canadá y Estados Unidos. Su ciclo de producción se desarrolla en 11 meses del año, lo que provee un constante flujo de efectivo, así como una segura fuente de empleo. 
de seguimiento y evaluación, y 3) innovación relacionada con el personal. En el primero destacan el uso de manuales de operación de maquinaria y equipo, el registro o bitácora diaria de experiencias así como el uso de instructivos de trabajo para cada una de las tareas de los procesos. Solamente uno de los productores encuestados desarrolla dos de las tres herramientas mencionadas (gráfica 1).

En seguimiento y evaluación se perciben carencias en la estructura operativa para compartir conocimiento en las empresas encuestadas, pues sólo tres de los productores implementan herramientas para estos mecanismos, siendo sólo un productor el que implementa el conjunto total. ${ }^{21}$ Las publicaciones conteniendo experiencias productivas (boletines y reportes) es una estrategia muy demandada por los productores estudiados; de hecho, es la de mayor implementación: tres de los cinco informantes la utilizan y dos la utilizan como única herramienta para desarrollar habilidades en procesos. Igual que en el caso de los materiales y documentos de apoyo, sólo un informante aplica el total de las herramientas (gráfica 2).

En contraste, y en cuanto a la innovación relacionada con el personal, la capacitación del personal, la contratación de personal con mayor experiencia, así como la obtención de certificaciones de calidad son prácticas implementadas por la mayoría de las empresas. Las reuniones para compartir y analizar aspectos propios de la producción así como el uso de manuales son practicadas sólo por dos de los productores encuestados (gráfica 3). Los temas que engloba la capacitación del personal son administrativos, organizacionales y técnicos, principalmente inocuidad.

\section{Mecanismos de estandarización}

Los productores mostraron seis tipos de certificaciones; cuentan con la certificación de producción orgánica, de sanidad y de innocuidad, es decir, las Buenas Prácticas Agrícolas (BPA) y las Buenas Prácticas de Manufactura (ВРм). Respecto de las certificaciones como procesos y empaques, tales categorías entran еn врм у вРА.

${ }^{21}$ Las empresas SPR de RL Kino y Hortofrutícola Siglo xxi no registraron la implementación de estrategias de escalamiento competitivo relacionadas con el seguimiento y evaluación de procesos. 


\section{Gráfica 1. Herramientas para el desarrollo de habilidades. Documentación de apoyo}
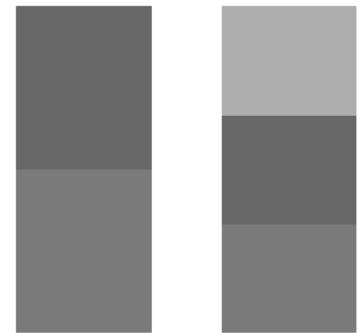

SPR de RL KINO Agric. del Desierto de Sonora

- Diagramas de flujo de procesos

- Registro o bitácora de experiencias

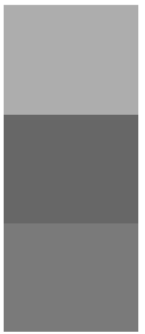

Hortofrut. Siglo XXI

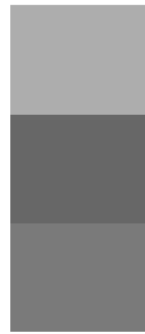

COROCIS

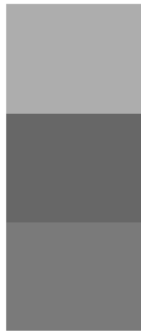

AGROCIR

- Instructivos de trabajo para las tareas/procesos

- Manuales de operación (equipo/maquinaria)

Fuente: Elaboración propia con información del cuestionario aplicado en septiembre de 2011.

Gráfica 2. Herramientas para el desarrollo de habilidades. Seguimiento y evaluación

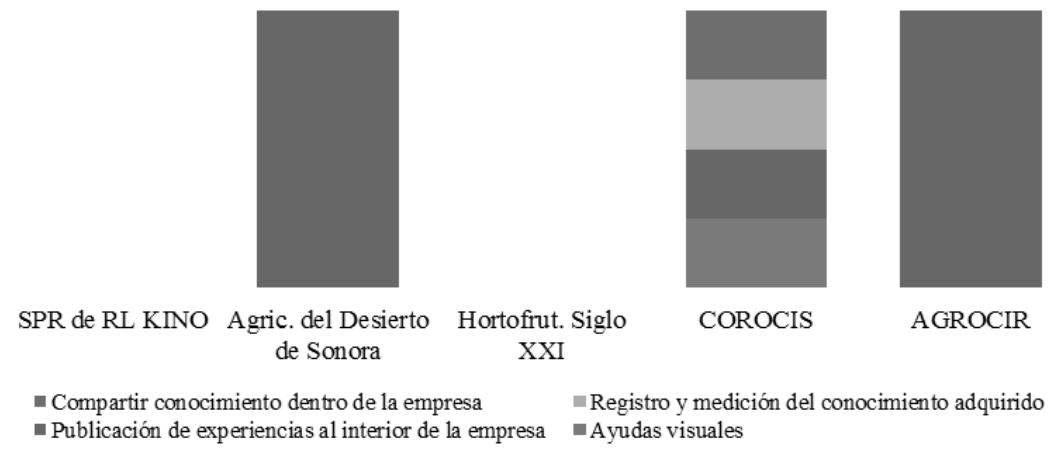

Fuente: Elaboración propia con información del cuestionario aplicado en septiembre de 2011. 


\section{Gráfica 3. Herramientas para el desarrollo de habilidades. Innovación relacionada al personal}

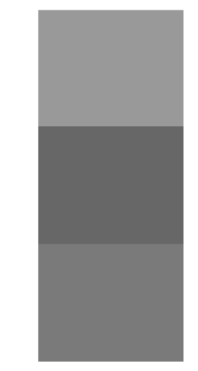

SPR de RL KINO

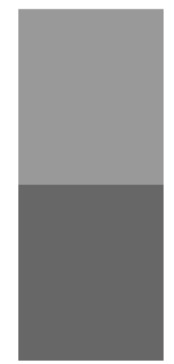

Agric. del Desierto de Sonora

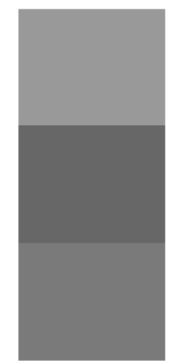

Hortofrut. Siglo XXI

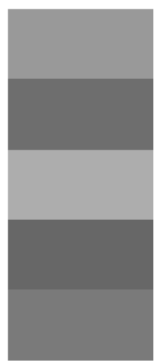

COROCIS

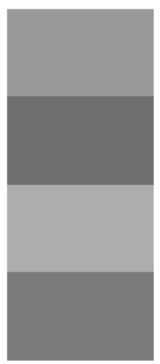

AGROCIR

- Certificaciones de calidad

neuniones para compartir experiencias

n Capacitación de personal

- Manuales

Contratación de personal con mayor experiencia

Fuente: Elaboración propia con información del cuestionario aplicado en septiembre de 2011.

Los protocolos de las BPA son lineamientos guía que tienen como objetivo asegurar un ambiente de trabajo limpio para todos los empleados, al tiempo que eliminan la contaminación en los productos agrícolas. En la Costa de Hermosillo su realización se basa en auditorías en los puntos de cultivo como las granjas de cielo abierto y casa sombra, así como a los grupos que realizan labores de cosecha. Las auditorías se realizan durante el ciclo de siembra y evalúan aspectos como trazabilidad, medios de producción, protección de los cultivos, sanidad y medios de fertilización. De igual manera, los empacadores deben cumplir con los protocolos de las BPM, que consisten en regulaciones que tienen por objetivo evitar la adulteración de los alimentos, además de ir en congruencia con las legislaciones de países como la Unión Americana y los de la Unión Europea, entre otros. Los puntos que se evalúan son el empaque, ${ }^{22}$ la refrigeración, el almacenaje y la distribución. Los elementos que se toman en cuenta son el control de plagas, el equipo para el procesamiento ${ }^{23}$ y la sanidad en los empleados.

${ }^{22}$ Procesos de selección, pesado y empacado de los productos agrícolas para su posterior comercialización y distribución.

${ }^{23}$ Es la tecnología utilizada para la selección, lavado, pesado y empaque de los productos. 
Cuadro 1. Certificaciones

\begin{tabular}{|l|c|c|c|}
\hline \multirow{2}{*}{ Productores } & \multicolumn{3}{c|}{ Tipo de certificación } \\
\cline { 2 - 4 } & 1 & 2 & 3 \\
\hline S.P.R. de R. L. KINO & Prod. orgánica & N/A & N/A \\
\hline $\begin{array}{l}\text { Agrícola del Desierto de Sonora S.A. } \\
\text { de C.V. }\end{array}$ & Prod. orgánica & N/A & N/A \\
\hline Compañía Hortofrutícola Siglo XXI & $\begin{array}{c}\text { Buenas } \\
\text { prácticas } \\
\text { agrícolas }\end{array}$ & $\begin{array}{c}\text { Buenas } \\
\text { prácticas de } \\
\text { manufactura }\end{array}$ & SENASICA \\
\hline coROcIS & Procesos & Prod. orgánica & N/A \\
\hline AGROCIR S.A. de C.V. & Empaques & N/A & N/A \\
\hline
\end{tabular}

Fuente: Elaboración propia con información del cuestionario aplicado en septiembre de 2011.

Mecanismos sobre información y adquisición de tecnologías

La captación de información sobre tecnologías es un elemento clave dentro del proceso de escalamiento competitivo de las empresas. Dentro de los productores evaluados en la Costa de Hermosillo se advierte una frecuente asistencia de eventos, conferencias, seminarios y/o cursos: tres de los encuestados hacen uso de este tipo de medios. La colaboración con universidades o centros de investigación también es común entre los productores; las publicaciones especializadas así como la información en internet son otras herramientas de gran demanda. La asistencia a ferias y exposiciones no es un mecanismo de uso frecuente (gráfica 4).

Dentro de los aspectos relacionados con asistencia y/o asesoría, la asistencia técnica, ya sea de clientes y/o proveedores, es la más significativa. La consultoría no es una fuente de información típica para los productores de la Costa de Hermosillo (gráfica 5).

Otras fuentes de información sobre tecnologías tienen que ver con la comunicación y colaboración con el resto de agentes de la cadena. Los proveedores de equipos y materiales proporcionan información de vanguardia en la materia, por lo que son buenas referencias para los produc- 
Gráfica 4. Información sobre nuevas tecnologías. Eventos, información especializada e internet y vínculos ies

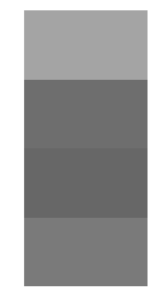

SPR de RL KINO

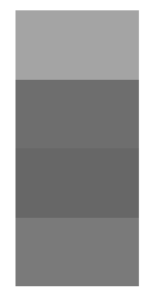

Agric. del Desierto Hortofrut. Siglo XXI de Sonora

$=$ Colab. IES o C. Investig.

- Public. especializadas e info. internet $=$ Ferias y exposiciones

$\|$ Conferencias, seminarios $\mathrm{y} / \mathrm{o}$ cursos $\|$ A sistencia a eventos

Fuente: Elaboración propia con información del cuestionario aplicado en septiembre de 2011.

\section{Gráfica 5. Información sobre nuevas tecnologías. Asistencia técnica y/o asesorías}

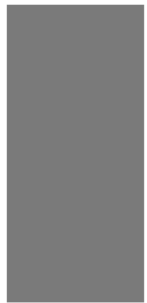

SPR de RL KINO

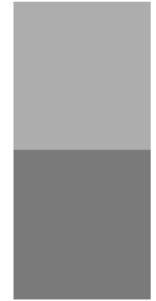

Agric. del Desierto de Hortofrut. Siglo XXI Sonora

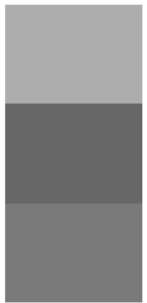

COROCIS

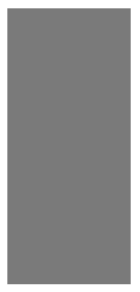

AGROCIR 


\section{Gráfica 6. Información sobre nuevas tecnologías. Colaboración con clientes, proveedores y/o competidores}

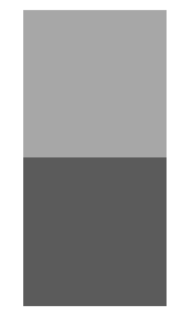

SPR de RL KINO

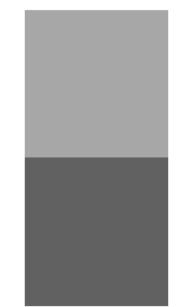

Agric. del Desierto de Hortofrut. Siglo XXI Sonora

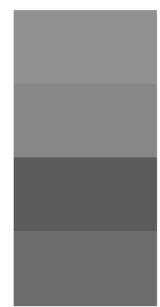

Empresas del sector - Proveedores diversos - Clientes

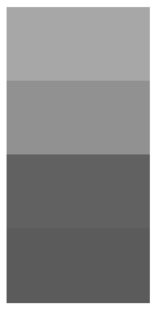

COROCIS

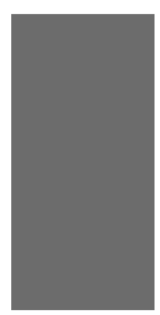

AGROCIR

IVisita a otras empresas - Competidores

Empresas aliadas

- Cámaras y asoc. Empres.

Fuente: Elaboración propia con información del cuestionario aplicado en septiembre de 2011.

Respecto de la adquisición de nuevas tecnologías, casi todas las empresas entrevistadas recurren ya sea a la adaptación o a la adquisición de equipo. La compra se hace directamente en ferias empresariales con una adaptación a las necesidades propias de la producción así como al entorno (gráfica 7). La adquisición de tecnología por medio del Departamento de Investigación y Desarrollo es una práctica poco común; ésta se realiza comúnmente por el área de producción. Se observa que la colaboración con clientes también influye en las decisiones respecto del acceso a la tecnología de estas empresas.

Los centros públicos de investigación y desarrollo, como el Instituto Nacional de Investigaciones Forestales, Agrícolas y Pecuarias (Inifap), son otros mecanismos óptimos para la adquisición de nuevas tecnologías. ${ }^{25}$ No obstante, la adquisición de tecnología vía las instituciones de educación superior (IES), como universidades, tecnológicos y centros de capacitación profesional y de asistencia técnica, es menos frecuente. Otro de los mecanismos que se evaluó, la adquisición propia de nuevos equipos e instituciones de pruebas, ensayos y certificaciones, resultó no ser practicado por las empresas estudiadas en la Costa de Hermosillo.

${ }^{25}$ Institución de investigación científica y tecnológica que pertenece al gobierno federal y cuyo objetivo es generar conocimiento e innovaciones tecnológicas en áreas agrícolas y pecuarias (http://www.inifap.gob.mx). 


\section{Gráfica 7. Adquisición de nuevas tecnologías. Fuentes y mecanismos utilizados}

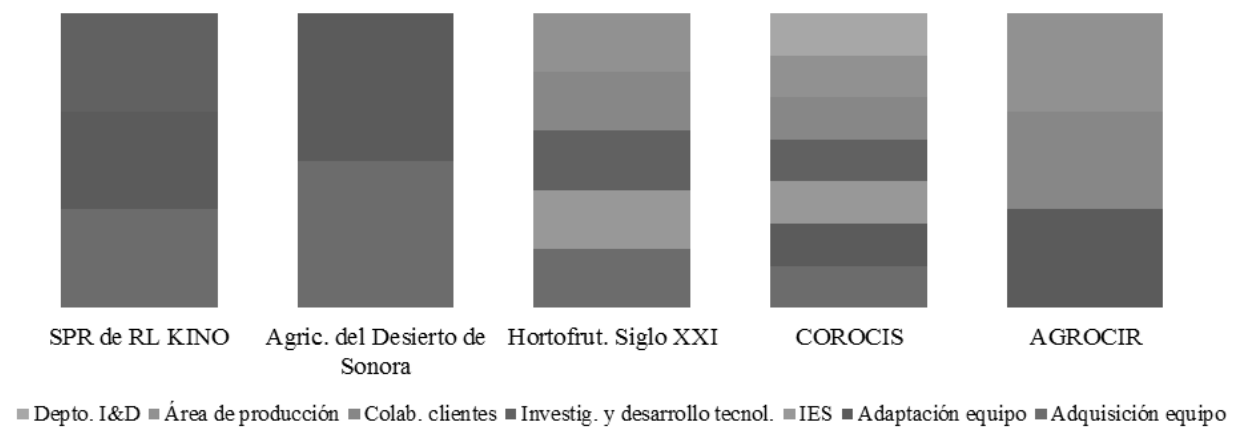

Fuente: Elaboración propia con información del cuestionario aplicado en septiembre de 2011.

\section{Escalamiento competitivo a nivel funciones organizacionales}

\section{Mecanismos de mercadotecnia}

La atención al mercado y a las necesidades del cliente es crucial en la competitividad de las empresas. Ello propicia un mayor conocimiento sobre las características del mercado que son de interés para la empresa. Respecto de las actividades de mercadotecnia, las empresas de la Costa de Hermosillo parecen concentrar acciones hacia el reconocimiento de sus mercados y las estrategias de venta, marketing y servicio al cliente. Sin embargo, ninguna de las empresas recurre al uso de estrategias de investigación de las tendencias de mercado (gráfica 8).

\section{Mecanismos de logística}

Dentro de las funciones organizacionales del escalamiento competitivo la logística desempeña un papel central. Considerada como "la cara de las empresas", esta área recibe las necesidades que presenta el cliente. Estos mecanismos son clave para desarrollar estrategias de comercialización. En lo que concierne a los productores de la Costa de Hermosillo encuestados, se observó que los mecanismos implementados más usuales son los cam- 


\section{Gráfica 8. Mecanismos de mercadotecnia}

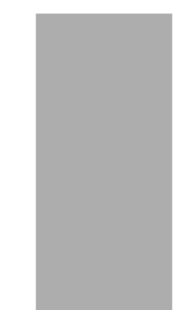

SPR de RL KINO
Agric. del Desierto de Sonora

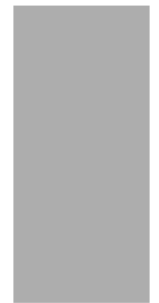

Hortofrut. Siglo XXI

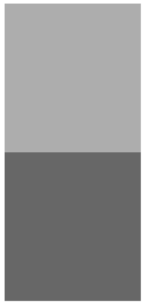

COROCIS

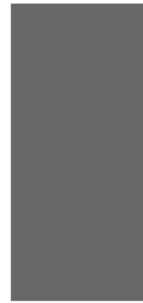

AGROCIR

ఐ Conocer más el mercado de interés @ Ventas, mercadotecnia y serv. cliente $\quad$ Investigación tendencias de mercado

Fuente: Elaboración propia con información del cuestionario aplicado en septiembre de 2011.

bios en el empaque o embalaje en los productos y el desarrollo de nuevos métodos de entrega aplicados a los productos existentes en la empresa (gráfica 9).

\section{Mecanismos gerenciales}

En lo que respecta a este punto, únicamente dos de las empresas encuestadas reflejan un desarrollo en las capacidades de toma de decisiones estratégicas como resultado de la implementación de mecanismos gerenciales. El desarrollo de mejores capacidades administrativas se muestra sólo en una empresa productora (gráfica 10). ${ }^{26}$

aiec de la agricultura orgánica de la zona sur de Baja California Sur

\section{Escalamiento competitivo a nivel producto}

La producción de hortalizas orgánicas en el sur de Baja California Sur constituye el nuevo esquema productivo adoptado por los núcleos comunitarios

${ }^{26}$ Algo que tampoco se advierte entre los productores de la zona es una mejor estructura organizacional. 


\section{Gráfica 9. Mecanismos de logística}

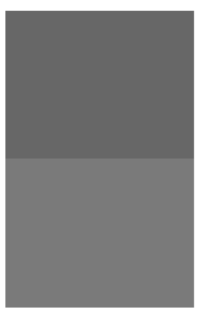

Hortofrut. Siglo XXI

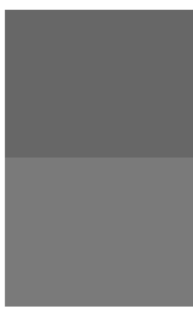

COROCIS

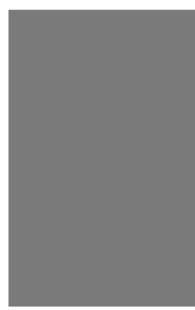

AGROCIR

- Nuevos métodos de entrega $\quad$ Cambios en el empaque o embalaje

Fuente: Elaboración propia con información del cuestionario aplicado en septiembre de 2011.

Gráfica 10. Mecanismos gerenciales. Innovación y/o mejores capacidades administrativas

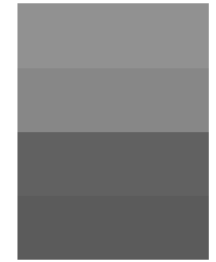

Hortofrut. Siglo XXI

- Capacidad de inversión

m Estructura de la empresa

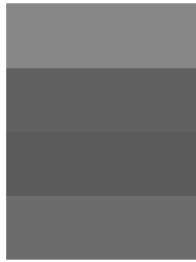

COROCIS

- Planeación financiera

- Decisiones estratégicas

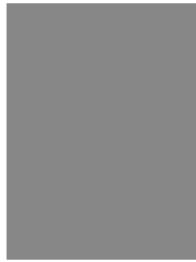

AGROCIR

- Negociación y ventas

- Capacitación administrativa

Fuente: Elaboración propia con información del cuestionario aplicado en septiembre de 2011.

ejidales; ello en respuesta a las necesidades de los comercializadores internacionales localizados en el estado de California, Estados Unidos. Con dicho patrón de cultivo, se maximizó el aprovechamiento de la ventana de comercialización debido a dos principales factores: 1) las condiciones climáticas favorables de la zona sur, y 2) la alta demanda de los productos por las fiestas decembrinas en Estados Unidos. A continuación se analizan los procesos de escalamiento seguidos por los productores de la referida región. 
Mecanismos para la mejora del producto

En la región sur, los principales cultivos orgánicos son el tomate en la variedad de tomate rojo y cherry; especias aromáticas como albahaca, tomillo y estragón, entre otras. La razón del porqué estos productos ocupan la mayor superficie sembrada se debe, en principio, a la petición de comercializadores norteamericanos, que a su vez están en contacto con las cadenas de supermercados y negocios minoristas, así como a las condiciones de suelo arenoso que permiten la adecuada absorción de agua. Los elementos de mayor diferenciación, respecto de otras zonas de cultivo, es el color y sabor del tomate y la albahaca procedente de Los Cabos, que gozan de un reconocimiento amplio entre los consumidores del estado de California.

De acuerdo con los productores y comercializadores, la textura y el sabor dulce de los tomates de la región se perciben como únicos. De igual forma, la albahaca, con su color verde intenso y sabor a anís, la hacen ser de los productos líderes de la región.

\section{Escalamiento competitivo a nivel procesos}

La producción orgánica conlleva el cumplimiento de una serie de estándares. Actualmente los consumidores se preocupan más por su salud, por lo que demandan seguridad e higiene en sus alimentos. Por ello los productores orgánicos de la zona sur de Baja California Sur han desarrollado mecanismos para cumplir estrictos estándares en integridad orgánica, calidad y seguridad alimenticia —impuestos por cadenas de supermercados e instituciones internacionales y exigidos por los compradores también internacionales-, con el auxilio de tecnología en la producción.

Mecanismos para el desarrollo de habilidades

de aprendizaje y mejora en los procesos

Dentro de este conjunto de herramientas destaca el registro de bitácoras, donde más de 95\% de los productores la utilizan; sin embargo, no sucede así para los instructivos de trabajo, diagrama de flujo y manuales de operación (gráfica 11). 
Gráfica 11. Herramientas para el desarrollo de habilidades. Materiales y apoyos visuales

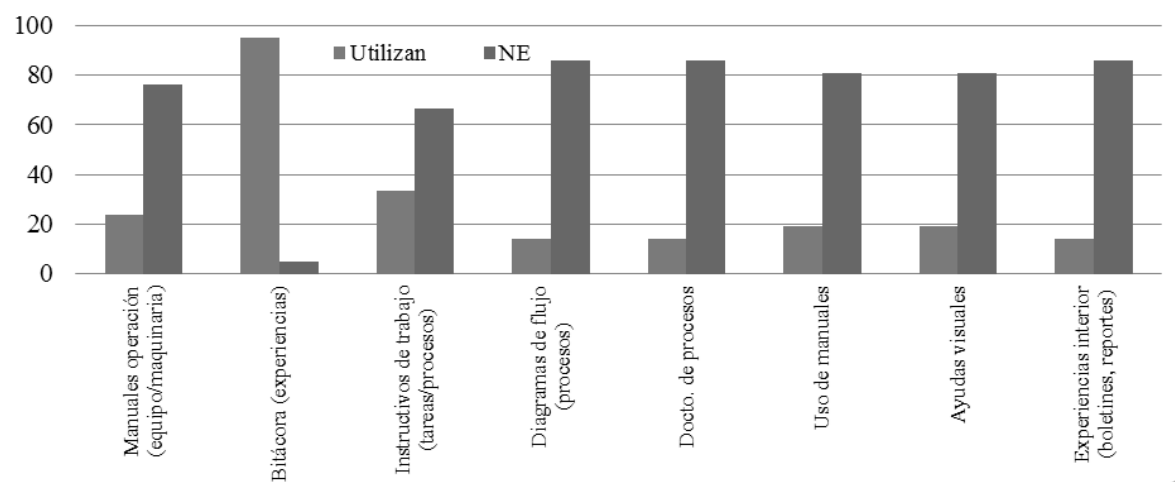

Fuente: Elaboración propia con información del cuestionario aplicado en julio de 2011.

En lo que respecta a las habilidades para incentivar el seguimiento y la evaluación, buena parte de éstas no son prioridad para la mayoría de los productores. La más utilizada es la obtención de certificaciones, tanto en producción como en innocuidad, con una observancia del $100 \%$. Le siguen las relacionadas con la capacitación del personal así como la contratación de personal con mayor experiencia, que son implementados por la mayoría de los productores: participación superior al 95\% y 50\%, respectivamente (gráfica 12 ).

Es curioso notar que tanto los productores como los empresarios carecen en su estructura operativa de sistemas para compartir conocimiento entre sus miembros; de igual manera, la evaluación del conocimiento, así como la publicación de información como boletines y reportes es una práctica llevada apenas por $15 \%$, salvo las ayudas visuales que tienen una observancia de apenas $20 \%$ de los productores encuestados. Las reuniones para compartir y analizar aspectos propios de la producción son practicadas solamente por $25 \%$ de los productores encuestados; la documentación en procesos y el uso de manuales presentan valores de 15 y $20 \%$ respec- 


\section{Gráfica 12. Herramientas para el desarrollo de habilidades. Seguimiento y evaluación}

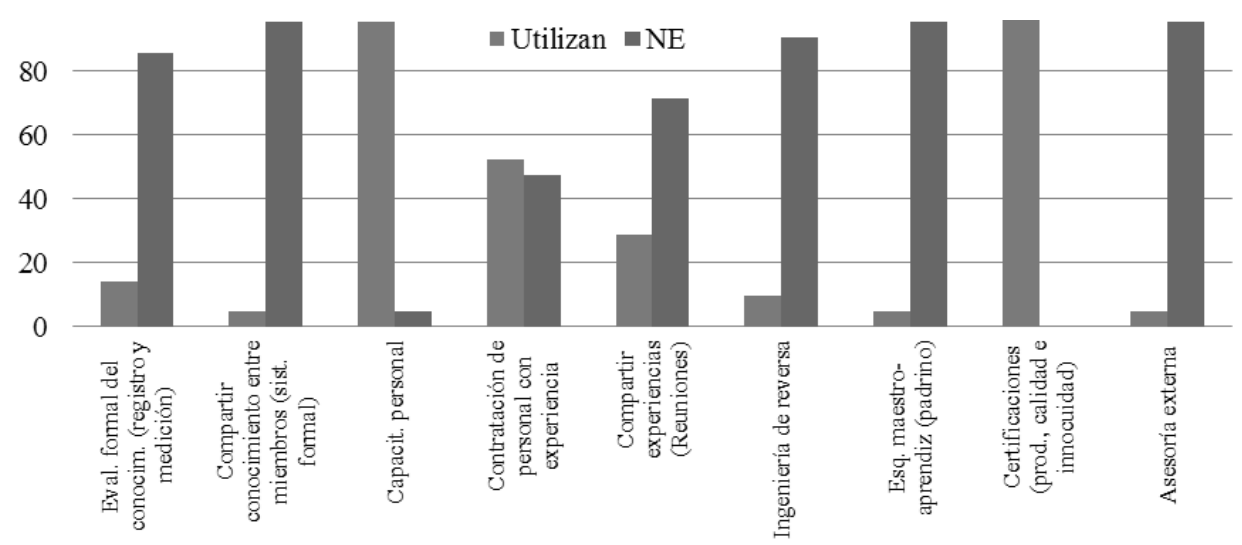

Fuente: Elaboración propia con información del cuestionario aplicado en julio de 2011.

tivamente. En contraste, la ingeniería de reversa apenas es aplicada por $10 \%$ de los productores ${ }^{27}$ y apenas $5 \%$ hace uso de asesoría externa. ${ }^{28}$

\section{Mecanismos de estandarización}

En lo concerniente a los mecanismos de estandarización, los productores mostraron seis tipos de certificaciones. La certificación de producción orgánica es practicada por $100 \%$ de los productores encuestados; la sanidad e innocuidad, es decir, la Buenas Prácticas de Campo y las Buenas Prácticas de Manufactura, tuvieron valores de $57 \%$ y $14 \%$ respectivamente. La certificación de bioterrorismo se refleja sólo por un productor, lo mismo que la correspondiente a sistemas de riego y sanidad vegetal otorgada por SENASICA (cuadro 2).

${ }^{27}$ Se entenderá por "ingeniería de reversa" a las adaptaciones o "hechicerías" realizadas a equipos comprados o adquiridos a través de un programa de ayuda gubernamental.

28 Entendida como la contratación expresa de los productores por servicios de consultaría especializada. 
Cuadro 2. Tipos de certificación

\begin{tabular}{|l|c|c|}
\hline \multicolumn{1}{|c|}{ Tipo de certificación } & Frecuencia & $\%$ \\
\hline Producción orgánica & 21 & 100 \\
\hline Buenas Prácticas Agrícolas (campo) & 12 & 57 \\
\hline Buenas Prácticas de Manufactura & 3 & 14 \\
\hline Bioterrorismo* & 1 & 5 \\
\hline Sanidad Vegetal & 1 & 5 \\
\hline Sistema de riego & 1 & 5 \\
\hline
\end{tabular}

* De acuerdo con Ibáñez (2006), se lo define como el medio de perpetración de atentados con armas biológicas, cuyos efectos dependen de la multiplicación de organismos causando enfermedades o muerte a personas, animales o plantas. Ahora bien, un arma biológica es aquella que alcanza efectos pretendidos por medio de la contagiosidad de microorganismos patógenos y otras entidades tales como virus, ácidos nucleicos infecciosos y priones (oms, 1970; Ibáñez, 2006).

Fuente: Elaboración propia con información del cuestionario aplicado en julio de 2011.

Mecanismos sobre información de tecnologías

En lo referente a información sobre tecnologías, se advierte la utilización homogénea de las siguientes herramientas: 1) asistencia a eventos, 2) asistencia técnica de clientes o proveedores, 3) colaboración con otras empresas del sector, 4) colaboración con proveedores, y 5) colaboración con universidades o centros de investigación (gráfica 13).

La asistencia a ferias y exposiciones es practicada por $26 \%$ de los productores. Atrae la atención que los productores no utilizan las conferencias, seminarios y cursos como fuentes de información sobre tecnologías, al presentar valores de 14 .

Por su parte, la colaboración con clientes es muy utilizada, con una incidencia superior a 40\%; sin embargo, las alianzas con otras empresas así como con proveedores de equipos y materiales no son utilizadas por la mayoría de los productores encuestados y presentan valores de utilización del 14\% (gráfica 14). 


\section{Gráfica 13. Información sobre nuevas tecnologías.}

Eventos, información especializada e internet y vínculos ies

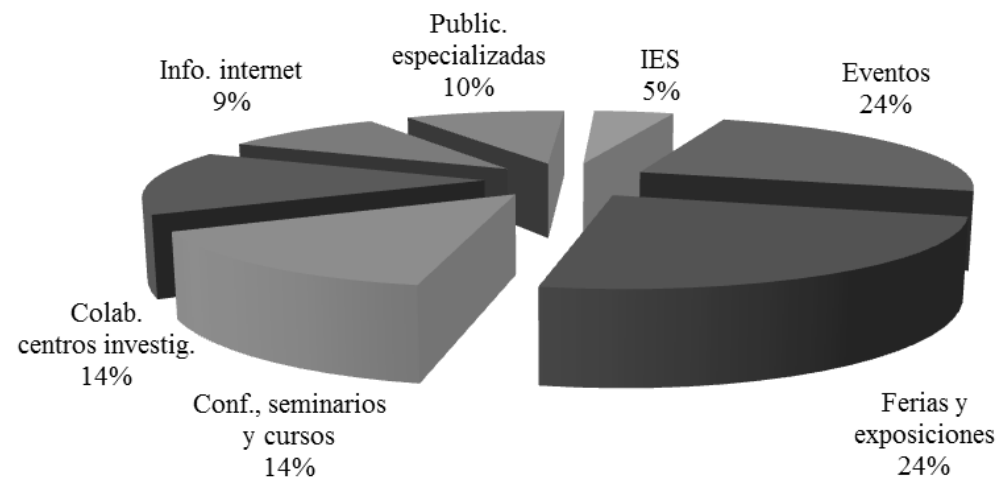

Fuente: Elaboración propia con información del cuestionario aplicado en julio de 2011.

Gráfica 14. Información sobre nuevas tecnologías. Colaboracíón con clientes, proveedores y/o competidores

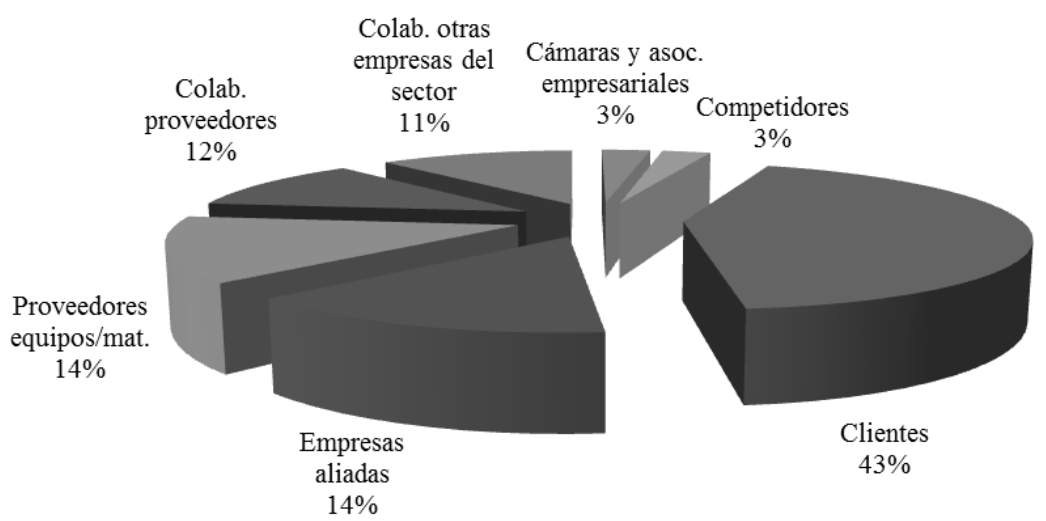

Fuente: Elaboración propia con información del cuestionario aplicado en julio de 2011. 
Finalmente, la gráfica 15 muestra el último segmento de los mecanismos de allegarse información tecnológica. La asistencia técnica de clientes o proveedores es el más utilizado con valores de $45 \%$. Asimismo, la visitas a otras empresas es el segundo mecanismo más utilizado con valores de $33 \%$. Se observa que las empresas de consultoría son la última fuente con un valor de $22 \%$.

Mecanismos de adquisición de nuevas tecnologías

La manera de adquirir nuevas tecnologías es a partir de la colaboración con clientes; estas acciones son llevadas a cabo por $41 \%$ de los productores encuestados y el Departamento de Investigación y Desarrollo (IyD) es utilizado por sólo 5\% (gráfica 16). Por su parte, la adaptación de maquinaria y equipo es otro de los mecanismos utilizados, con 33\% (gráfica 16).

Las áreas de producción son otro mecanismo para la adquisición de nuevas tecnologías. Nuevamente, los centros de investigación y desarrollo tecnológico son poco utilizados, con valores de 19\%. El mismo comportamiento muestran las capacitaciones así como las instituciones de educación con $6 \%$ (gráfica 17).

\section{Escalamiento competitivo a nivel funciones organizacionales}

\section{Mecanismos de mercadotecnia}

En lo que respecta a actividades de mercadotecnia, cabe resaltar que la contratación de servicios de investigación de mercados, así como áreas de venta y mercadotecnia representan 12 y $25 \%$ respectivamente. No obstante, un mayor conocimiento sobre las características del mercado presenta niveles de participación de $60 \%$ (gráfica 18).

\section{Mecanismos de logística}

En lo referente a la logística, los productores se muestran dispuestos a hacer cambios en los tipos de empaque y embalaje del producto dependiendo de las exigencias que reciban, así como utilizar métodos de entrega de productos ya existentes en la empresa (gráfica 19). 


\section{Gráfica 15. Información sobre nuevas tecnologías. Asistencia técnica y/o asesorías}

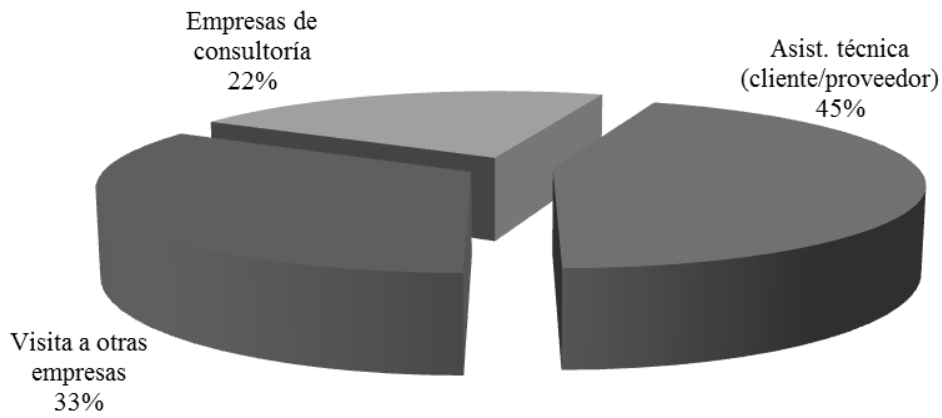

Fuente: Elaboración propia con información del cuestionario aplicado en julio de 2011.

\section{Gráfica 16. Adquisición de nuevas tecnologías. Fuentes y/o mecanismos}

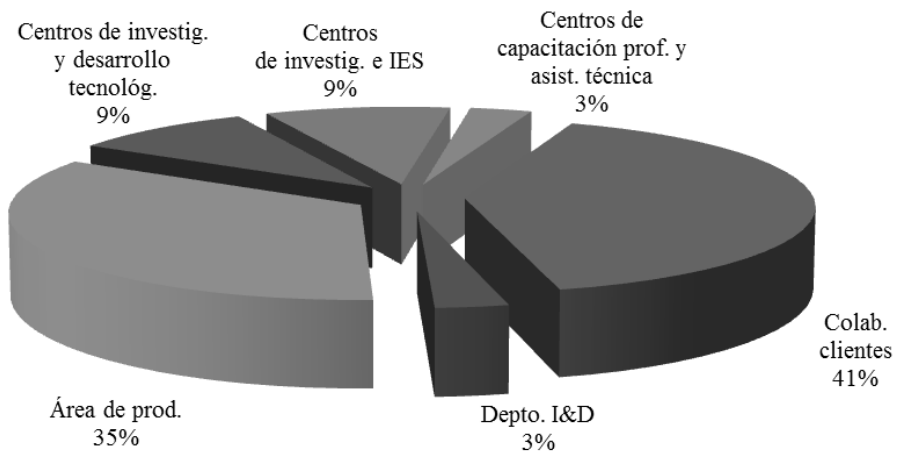

Fuente: Elaboración propia con información del cuestionario aplicado en julio de 2011. 


\section{Gráfica 17. Adquisición de nuevas tecnologías. Acciones desarrolladas}

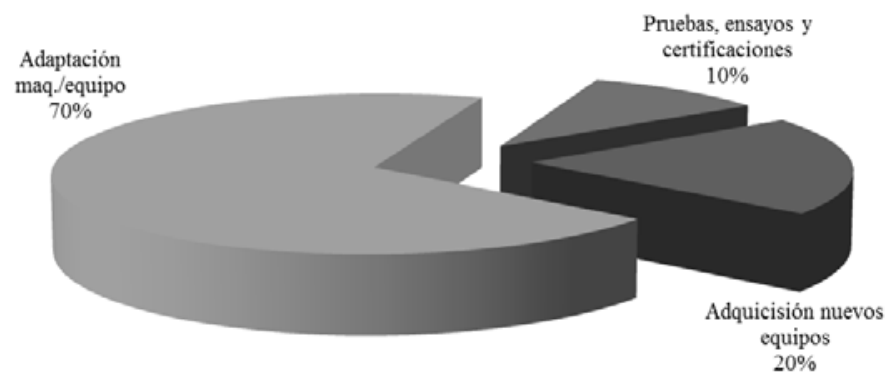

Fuente: Elaboración propia con información del cuestionario aplicado en julio de 2011.

\section{Gráfica 18. Habilidades gerenciales. \\ Mecanismos en los productores}

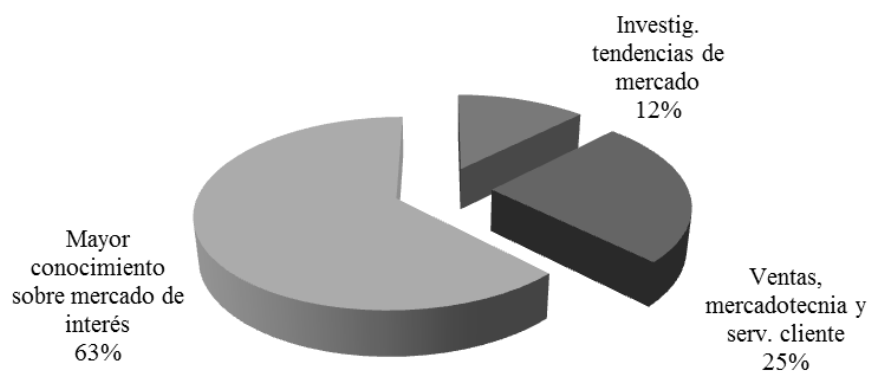

Fuente: Elaboración propia con información del cuestionario aplicado en julio de 2011. 


\section{Gráfica 19. Mecanismos de logística}

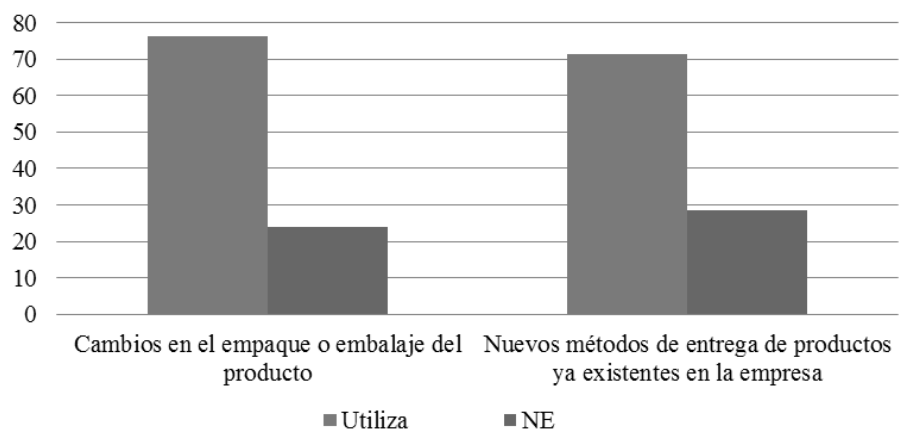

Fuente: Elaboración propia con información del cuestionario aplicado en julio de 2011.

\section{Mecanismos gerenciales}

Finalmente, la gráfica 20 muestra que cerca de $80 \%$ de los productores posee una mejor capacidad de toma de decisiones estratégicas en lo concerniente a la producción. Sin embargo, el resto de las variables no muestra el mismo nivel de observancia, tales como una mejor estructura organizacional o una mejor planeación financiera, ni mayores capacidades de inversión o capacitación administrativa.

\section{Conclusiones}

El escalamiento competitivo de la actividad agrícola en ambas zonas muestra signos de transformación como resultado de un anclaje a la dinámica de las RGP. Es claro que dicha modernización presenta matices debido a las características climáticas y circunstancias de cada localidad. En el escalamiento en productos, las zonas de estudio orientan su producción hacia cultivos intensivos como hortalizas y frutales destinados casi en su totalidad a los mercados internacionales. Para ello utilizan técnicas de producción altamente tecnificadas, como es el caso de la Costa de Hermosillo, y amigables con el medio ambiente, como en la zona sur de Baja California Sur. 


\section{Gráfica 20. Mecanismos gerenciales. Innovación y mejoras}

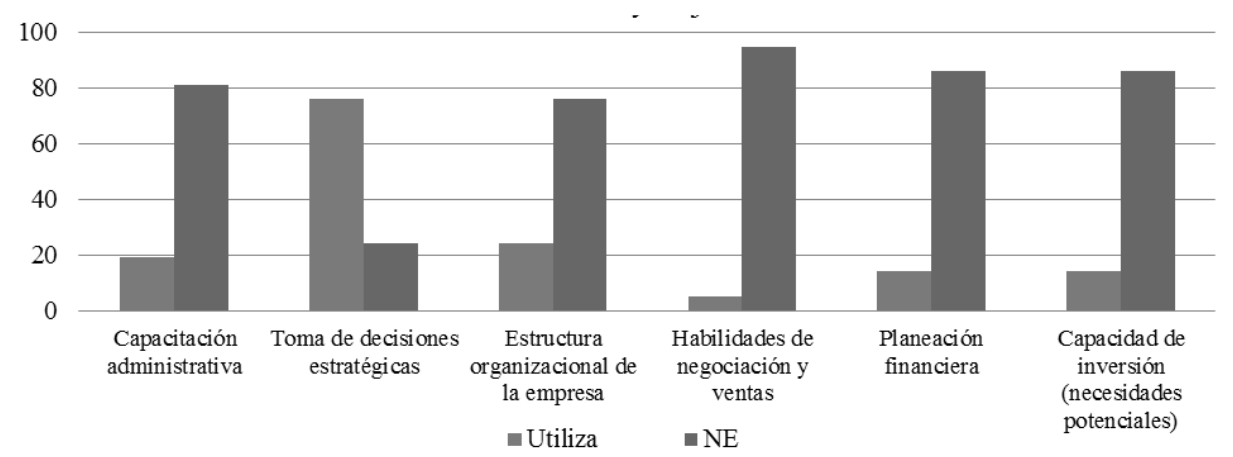

Fuente: elaboración propia con información del cuestionario aplicado en julio de 2011.

Por su parte, en cuanto al escalamiento en funciones organizacionales, las localidades muestran una mayor comprensión de las necesidades de los consumidores a través de estudios de mercado. Esta información se traduce en cambios en empaques y embalajes principalmente. En la dimensión gerencial, muestran mayor capacidad de toma de decisiones y administrativa al existir departamentos claramente identificados en su organigrama con personal calificado para realizar las tareas correspondientes.

Donde se observan tanto similitudes como diferencias es en escalamiento en procesos. En principio, las similitudes se encuentran en los procesos de producción, donde es claro el uso de mecanismos para incrementar habilidades tales como manuales de operación, el diseño de instructivos para cada tarea así como bitácoras para registrar sucesos y experiencias como resultado del apego y cumplimiento de certificaciones internacionales como las BPA, las BPM y la producción orgánica. Este hecho crea un círculo de confianza frente a los mercados internacionales al observar protocolos de seguridad globalmente aceptados.

Sin embargo, las diferencias se presentan en la dimensión de tecnologías tanto en información acerca de ellas como en su adquisición. Como mecanismos de información, los productores de la Costa de Hermosillo además de asistir a eventos y seminarios, recurren a publicaciones cientí- 


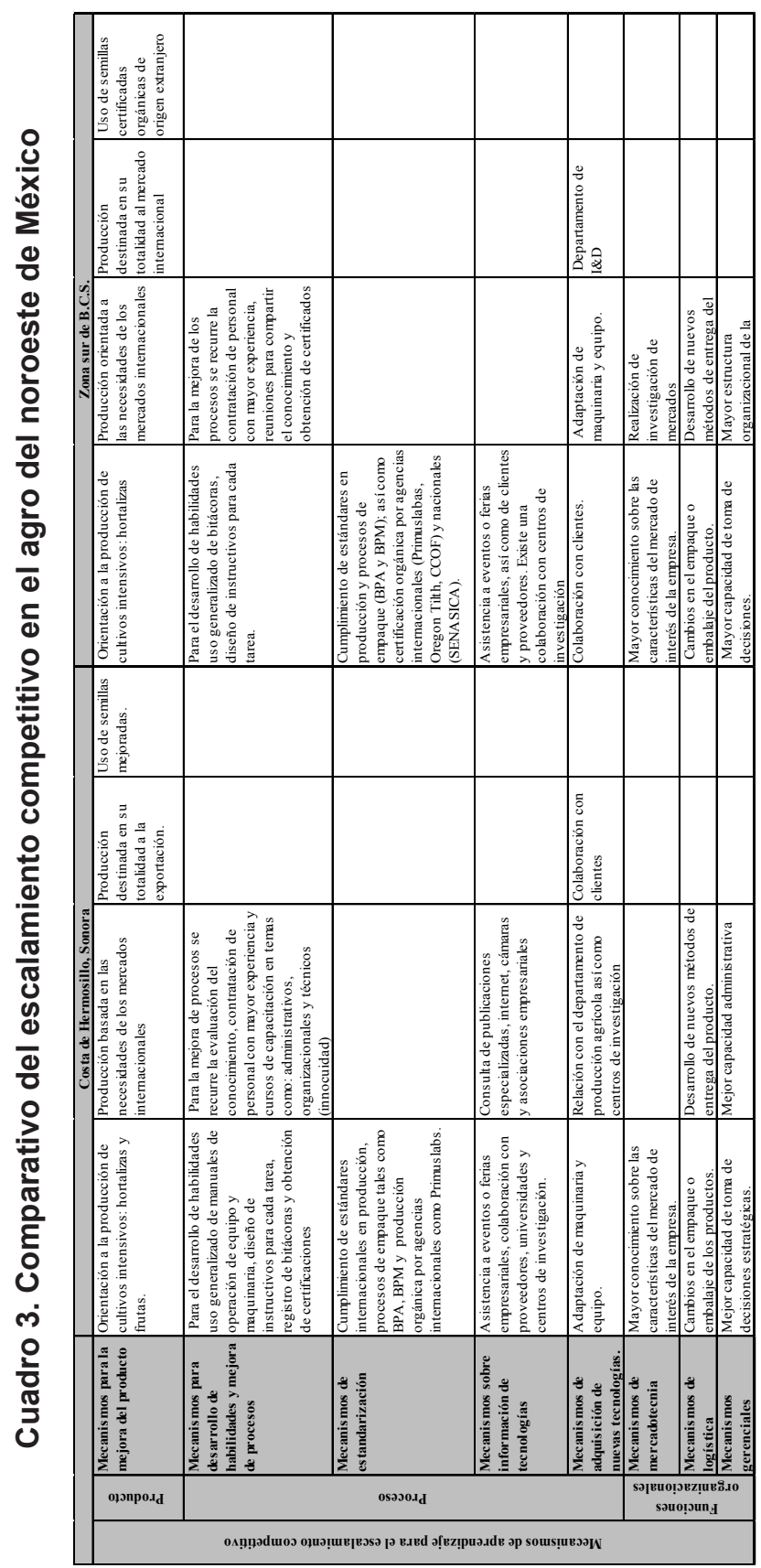


ficas como resultado de su vinculación con instituciones de investigación y universidades. Esta vinculación se da a través de proyectos de investigación de tipo informal, la cual favorece la adecuada adquisición de maquinaria y equipo. Por su parte, los productores de la zona sur de Baja California Sur tienen como fuente de información sólo a sus clientes y proveedores, existiendo poca vinculación con centros de investigación al no existir proyectos de tipo formal o informal. La adquisición de maquinaria y equipo tiene su sustento solamente en la información que los clientes y proveedores otorgan, lo que puede ser o no adecuado.

\section{Bibliografía}

Acosta Martínez, A. I. y B. D. Avendaño (2010), "Especialización comercial del subsector hortofrutícola en el TLCAN”, en C. J. Maya y M. C. Hernández (eds.), La encrucijada del México rural. Constrastes regionales en un mundo desigual, Mexico, Universidad Autónoma de Sinaloa, Centro de Investigación en Alimentación y Desarrollo, Asociación Mexicana de Estudios Rurales, Juan Pablos Editor.

Dodgson, M. (1991), “Technology Learning, Technology Strategy and Competitive Pressures”, British Journal of Management, vol. 2, núm. 3, pp. 133-149.

Estrada, J. L. y M. J. Martínez (2007), Propuesta de acción integrada en la Costa de Hermosillo, Sonora. Tesina para obtener el diploma de Especialidad en Gestión Integrada de Ciencias Hidrológicas. El Colegio de Sonora.

Gereffi, G. (1999), "International Trade and Industrial Upgrading in the Apparel Commodity Chain", Journal of International Economics, vol. 48, núm. 1, pp. 37-70.

—, M. Korzeniewicz y R. P. Korzeniewicz (1994), "Introduction: Global Commodity Chains", Gereffi y Korzeniewicz (eds.), Commodity Chains and Global Capitalism, pp. 1-14.

Gibbon, P. (2001), "Upgrading Primary Production: A Global Commodity Chain Approach”, World Development, vol. 29, núm. 2, pp. 345-363.

Humphrey, J. (2005), "Shaping Value Chains for Development: Global Value Chains in Agribusiness", Deutsche Gesellschaft für Technische Zusammenarbeit, Alemania.

— y O. Memedovic (2006), Global Value Chains in the Agrifood Sector, Viena, Austria.

Ibáñez Ferrandiz, I. (2006), Bioterrorismo: la amenaza latente, Madrid, Universidad San Pablo, ceu, Instituto de Estudios Europeos. 
Kaplinsky, R. y M. Morris (2001), A Handbook for Value Chain Research, vol. 113, IDRC.

López Placencia, I. y R Gomis (2004), "Ventajas competitivas de las tecnologías de la información: el sector de la electrónica en Tijuana", en J. Carrillo y R. Partida, La industria maquiladora mexicana: aprendizaje tecnológico, impacto regional y entornos institucionales, Tijuana, El Colegio de la Frontera Norte.

Marsh, R. y D. Runsten (2000), "The Organic Produce Niche Market: Can Mexican Smallholders be Stakeholders", G. Rodríguez y R. Snyder (eds.), Strategies for Resource Management, Production, and Marketing in Rural Mexico, La Jolla, Center for US-Mexican Studies, University of California, San Diego/La Jolla.

Martínez, J. M., R. F. de Salud, A. C. Ambiente, C. Reed y R. Fronteriza (2002), Acuíferos y libre comercio: el caso de la Costa de Hermosillo, Hermosillo, Son., Red Fronteriza de Salud y Ambiente, AC Cyrus Reed Texas, Center for Policy Studies.

— (2003), Acuíferos y agroquímicos en una región fronteriza: retos y oportunidades del TLCAN para la agricultura mexicana, Hermosillo, Son., Red Fronteriza de Salud y Ambiente, Universidad de Sonora, Comisión de Cooperación Ambiental.

Mora, C. S. (1981), "La agricultura comercial de los distritos de riego en México y su impacto en el desarrollo agrícola", Boletín del Instituto de Geografía, pp. $145-181$.

Moreno Vázquez, José Luis (2006), Por abajo del agua. Sobreexplotación y agotamiento del acuífero de la Costa de Hermosillo, 1945-2005, Hermosillo, El Colegio de Sonora.

Murillo-Amador, B., S. R Toyes Avilés y F. A. Beltrán-Morales (2006), "Productores orgánicos del Cabo: aspectos generales", en B. Murillo-Amador, F. A. Beltrán, J. L. García y L. Fenech Larios (eds.), La agricultura orgánica en Baja California Sur, México, Universidad Autónoma de Baja California Sur, Centro de Investigaciones Biológicas del Noroeste.

Rodríguez, J. M. M. (2003), Acuíferos y agroquímicos en una región fronteriza: retos y oportunidades del TLCAN para la agricultura mexicana, Hermosillo, Son., Red Fronteriza de Salud y Ambiente, Universidad de Sonora, Comisión de Cooperación Ambiental.

— oms (1970), Health Aspects of Chemical and Biological Weapons: Report of a wHO Group of Consultants, Ginebra, Organización Mundial de la Salud (Traducción realizada por la Organización Panamericana de la Salud, 2003).

Vera-Cruz, Alexandre y Gabriela Dutrénit (2009), "Derramas de las ETN a través de la movilidad de los trabajadores. Evidencia de pymes de maquinados en Ciudad Juárez", en Gabriela Dutrénit (coord.), Sistemas regionales de innovación: un espacio para el desarrollo de las PyMEs. El caso de la industria de maquinados industriales, México, Universidad Autónoma Metropolitana. 


\section{Sitios de internet}

http://tilth.org/

http://www.ams.usda.gov/AMsv 1.0/getfile?dDocName=sTELPRDC5057305

http://www.ams.usda.gov/AMsv1.0/NOP

http://www.inifap.gob.mx

www.delcabo.com

www.fda.gov

www.jacobsfarm.com

www.conagua.gob.mx

www.primuslabs/services/audits

www.senasica.gob.mx

Artículo recibido el 27 de febrero de 2012.

Tercera versión aprobada el 13 de septiembre de 2012. 